University of South Florida

DIGITAL COMMONS

Digital Commons @ University of

@ UNIVERSITY OF SOUTH FLORIDA

South Florida

$12-1994$

\title{
Accuracy Assessment of the Large-scale Dynamic Ocean Topography from TOPEX/POSEIDON Altimetry
}

\author{
B. D. Tapley \\ University of Texas at Austin \\ D. P. Chambers \\ University of Texas at Austin, donc@usf.edu \\ C. K. Shum \\ University of Texas at Austin \\ R. J. Eanes \\ University of Texas at Austin \\ J. C. Ries \\ University of Texas at Austin
}

See next page for additional authors

Follow this and additional works at: https://digitalcommons.usf.edu/msc_facpub

Part of the Marine Biology Commons

\section{Scholar Commons Citation}

Tapley, B. D.; Chambers, D. P.; Shum, C. K.; Eanes, R. J.; Ries, J. C.; and Stewart, R. H., "Accuracy Assessment of the Large-scale Dynamic Ocean Topography from TOPEX/POSEIDON Altimetry" (1994). Marine Science Faculty Publications. 1434.

https://digitalcommons.usf.edu/msc_facpub/1434

This Article is brought to you for free and open access by the College of Marine Science at Digital Commons @ University of South Florida. It has been accepted for inclusion in Marine Science Faculty Publications by an authorized administrator of Digital Commons @ University of South Florida. For more information, please contact digitalcommons@usf.edu. 


\section{Authors}

B. D. Tapley, D. P. Chambers, C. K. Shum, R. J. Eanes, J. C. Ries, and R. H. Stewart 


\title{
Accuracy assessment of the large-scale dynamic ocean topography from TOPEX/POSEIDON altimetry
}

\author{
B. D. Tapley, D. P. Chambers, C. K. Shum, R. J. Eanes, and J. C. Ries \\ Center for Space Research, University of Texas at Austin
}

\author{
R. H. Stewart \\ Department of Oceanography, Texas A\&M University, College Station
}

\begin{abstract}
The quality of TOPEX/POSEIDON determinations of the global scale dynamic ocean topography have been assessed by determining mean topography solutions for successive 10-day repeat cycles and by examining the temporal changes in the sea surface topography to identify known features. The assessment is based on the analysis of TOPEX altimeter data for cycles 1 through 36. Important errors in the tide model used to correct the altimeter data have been identified. The errors were reduced significantly by use of a new tide model derived with the TOPEX/POSEIDON measurements. Maps of the global 1-year mean topography, produced using four of the most accurate models of the marine geoid, show that the largest error in the dynamic ocean topography is now the uncertainty in the geoid. Temporal variations in the spatially smoothed maps of the annual sea surface topography show expected features, such as the known annual hemispherical sea surface rise and fall and the seasonal variability due to monsoon influence in the Indian Ocean. Changes in the sequence of 10-day topography maps show the development and propagation of an equatorial Kelvin wave in the Pacific beginning in December 1992 with a propagation velocity of approximately $3 \mathrm{~m} / \mathrm{s}$. The observations are consistent with observed changes in the equatorial trade winds, and with tide gauge and other in situ observations of the strengthening of the $1992 \mathrm{El}$ Niño. Comparison of TOPEX-determined sea surface height at points near oceanic tide gauges shows agreement at the $4 \mathrm{~cm}$ RMS level over the tropical Pacific. The results show that the TOPEX altimeter data set can be used to map the ocean surface with a temporal resolution of 10 days and an accuracy which is consistent with traditional in situ methods for the determination of sea level variations.
\end{abstract}

\section{Introduction}

The U.S. Global Change Research Program has noted that an understanding of the role of the oceans in the overall heat flux of the planet is of critical importance. Almost all solar radiance reaching the oceans is absorbed and stored. Ocean currents and the atmospheric circulation transport heat stored in the tropics to higher latitudes, thereby modulating the latitudinal temperature variations. The relative proportion of heat carried by the ocean's circulation, however, is poorly known. Consequently, developing an understanding of the ocean circulation and predicting its longterm change are critical elements in global change studies.

Satellite altimeters are particularly useful for studies of the ocean's circulation [Wunsch and Gaposchkin, 1980], because altimeter measurements of the ocean's surface topography can be converted directly to surface geostrophic current velocity through the geostrophic relation. Hence accurate global measurements of the ocean topography over decadal periods are required for studies of the global ocean circulation [TOPEX Science Working Group, 1981].

Sea surface height is influenced not only by surface geostrophic currents, but also by surface waves, tides, atmospheric pressure

Copyright 1994 by the American Geophysical Union.

Paper number $94 \mathrm{JC} 01827$.

0148-0227/94/94JC-01827\$05.00 variations, and the marine geoid. Further, the altimeter measurement of sea surface height is affected by the ionosphere, the wet and dry components of the atmosphere, and most notably, the orbit of the satellite. These effects must be removed from the altimeter measurements to obtain the features related to the ocean circulation. With the exception of the ionosphere, whose effects can be eliminated by using a dual-frequency altimeter, and the wet troposphere, which can be measured by the microwave radiometer, corrections for each of the remaining effects are determined by using models for each phenomenon. The model fidelity determines the accuracy of the individual corrections, and the overall accuracy of the altimeter height measurement is limited by the accuracy of these corrections.

The TOPEX/POSEIDON (T/P) mission was designed to allow ocean surface topography to be measured with a global RMS accuracy better than $13 \mathrm{~cm}$ [Stewart et al., 1986]. The radial orbit error, which has been a primary limitation in previous satellite altimeter missions, was identified as the primary error source in the prelaunch TOPEX error budget. After postlaunch model improvement a radial orbit accuracy of less than $4 \mathrm{~cm}$ RMS for the TOPEX satellite, using continuous 10-day arcs, can be obtained [Tapley et al., this issue]. The addition of the second frequency on the TOPEX altimeter allows an overall height measurement accuracy better than $4 \mathrm{~cm}$ RMS, and the postlaunch error budget for a single height measurement, averaged over $1 \mathrm{~s}$, is around $5 \mathrm{~cm}$ RMS [Fu et al., this issue]. The following discussions consider the accuracy with which these altimeter measure- 
ments can recover the dynamic ocean surface topography, with particular emphasis on the accuracy with which time variations in the ocean surface topography can be observed. The effects of geoid and ocean tide model error are assessed. Finally, the ability to monitor seasonal variations in the mean topography and the variation of the topography for successive 10-day repeat cycles are described.

\section{Oceanographic Phenomena}

The use of satellite altimeter data to study ocean phenomena has been approached from two basic points of view: (1) the determination and analysis of the absolute height of the ocean surface and (2) the analysis of the variability of these ocean heights with time. Each of the basic studies requires accurate altimeter measurements from the TOPEX/POSEIDON mission, but the variability studies can be performed in a way which minimizes the effects of geoid and orbit error. If an accurate orbit is provided, the mean ocean circulation can be determined by differencing the absolute sea surface heights from an appropriate geoid. Both geoid and orbit errors have direct influence on this approach.

Previous determinations of the long-wavelength components of the ocean surface topography have been limited primarily by geoid and orbit error, with ocean tide model error another important contributor [Tai and Wunsch, 1984; Engelis and Rapp, 1984; Zlotnicki et al., 1989; Tapley et al., 1988; Nerem et al., 1990; Shum et al., 1990, 1994; Koblinsky et al., 1992]. Currently, the geoid error limits the recovery of the absolute topography to wavelengths of the order of $1600 \mathrm{~km}$ or longer. However, with an accurate orbit, the temporal variations in the topography change can be determined to smaller scales. The separation of seasonal and episodic ocean surface signals from tidal-induced signals requires an accurate ocean tide model. Although previous efforts have been partially successful, the use of satellite altimeter data for the improvement of the ocean tide models has been limited by orbit error [Cartwright and Ray, 1990; Ray, 1993]. The orbit for the TOPEX/POSEIDON mission was selected to allow use of the altimeter data for tide model improvement as a specific objective [Parke et al., 1987], and the accurate orbits for this mission allow a significant improvement in the tide models [ $\mathrm{Ma}$ et al., this issue]. This improved tide model has been used to obtain the results presented here.

\section{Altimeter Data Preprocessing}

The altimeter data analyzed are the TOPEX geophysical data records (GDRs), provided by the NASA Jet Propulsion Laboratory [Callahan, 1993]. Corrections were applied for the effects of ionospheric delay, the wet and dry tropospheric delays, the sea state bias, the effects of spacecraft center-of-mass migration, and the effects of solid, ocean and pole tides. Additional corrections for the effects of atmospheric pressure on the ocean surface were applied by using the GDR dry tropospheric corrections to infer an inverted barometer correction. After the corrections for the geophysical, atmospheric, and instrument effects were applied, the individual altimeter measurement was edited if it was over land or ice, or if any of the following criteria were satisfied: (1) spacecraft attitude $>0.45^{\circ}$ from nadir, (2) $H_{1 / 3}=0.0 \mathrm{~m}$ or $>20 \mathrm{~m}$, (3) standard deviation of $H_{1 / 3}>1 \mathrm{~m}$, (4) measurement standard deviation $>20 \mathrm{~cm}$, (5) automatic gain control (AGC) $>100 \mathrm{~dB},(6)$ standard deviation of $\mathrm{AGC}>0.15 \mathrm{~dB},(7)$ ocean tide height $>10$ $\mathrm{m}$, (8) $0 \mathrm{~cm}>$ wet tropospheric correction $>40 \mathrm{~cm}$, (9) dry tropospheric correction $<-3 \mathrm{~m}$ or $>+2 \mathrm{~m},(10)$ solid Earth tide $>1 \mathrm{~m}$, and (11) |sea surface height (SSH) - geoid $\mid>15 \mathrm{~m}$.
To improve the processing efficiency and to eliminate the high-frequency components of the marine geoid, altimeter normal points were created. The high-frequency ocean signal above degree and order 70 was removed by adding the difference between the $70 \times 70$ Joint Gravity Model-2 (JGM-2) geoid and a high-frequency mean sea surface to the altimeter measurement [Nerem et al., 1990]. A line was fit to the 1-s altimeter data in a 10-s window and then evaluated at the midpoint of the window to compute a normal point measurement. Direct altimeter data were edited if (1) the magnitude of the altimeter height correction $>6$ $\mathrm{m}$, (2) the magnitude of the difference between a University of Texas Center for Space Research (UT/CSR) mean sea surface and the Ohio State University (OSU) $360 \times 360$ geoid $>3 \mathrm{~m}$, (3) the magnitude of the geoid gradient $>9 \mathrm{~m} / \mathrm{deg}$, and (4) the water depth $<10 \mathrm{~m}$. These criteria edited about $2 \%$ of the original data. A normal point was edited if (1) the number of altimeter observations in any 10-s window $<4$, or (2) the normal point RMS $>20$ $\mathrm{cm}$. After passing the precise orbit through the altimeter normal points, a final editing criteria was applied in which points were edited if (1) the residual exceeded $60 \mathrm{~cm}$, (2) the ocean depth was less than $100 \mathrm{~m}$, (3) the geoid gradient exceeded $6 \mathrm{~m} / \mathrm{deg}$, or (4) the ocean tide correction was missing. This typically edited about $7 \%$ of the remaining data, but these data were dominantly near the shoreline or in areas of steep geoid gradients.

\section{Accuracy of Dynamic Topography Height Measurement}

The accuracy of the dynamic ocean topography measurement, computed as the sea surface height above a reference ocean geoid, depends on the accuracy of the altimeter measurement and its corrections, the accuracy of the reference ocean geoid model, and the accuracy of the satellite height measurement. The altimeter measurement may contain a significant bias, but the bias can be removed by determining a global mean from the data set. While many of the altimeter corrections are calculated from models, the largest errors are associated with the geoid, the inverted barometer, and the ocean tide corrections. The inverted barometer correction accounts for the effect of the atmospheric pressure on the ocean topography, which causes a depression of approximately $1 \mathrm{~cm}$ in the ocean surface for every $1 \mathrm{mbar}$ increase in pressure. The importance of the inverted barometer correction for altimeter studies has made it a topic of significant current activity [Dickman, 1988; Tai, 1993]. Relations from the TOPEX GDR manual [Callahan, 1993] were used to infer the inverted barometer correction. Changes in the atmospheric pressure were computed relative to a mean pressure of 1010.6 mbar, the global mean pressure inferred from a 2-year average of the global sea level atmospheric pressure from the European Centre for MediumRange Weather Forecasts.

The height of the satellite above the reference ellipsoid is another important error source and has been a limiting factor in previous satellite altimeter missions. The orbits used in this study have been computed at UT/CSR using models consistent with the TOPEX GDR models, and they have an estimated radial orbit accuracy of less than $4 \mathrm{~cm}$ [Tapley et al., this issue].

The TOPEX/POSEIDON GDRs were distributed with the Cartwright and Ray [1990] ocean tide model, which is based on 2 years of Geosat altimeter data. Analysis of the initial TOPEX altimeter data indicated that ocean tide modeling error was significant in the TOPEX altimeter data [Ma et al., this issue] and was adversely influencing the determination of sea surface topography. The left column of Plate 1 shows topography anomalies for cycles 16 and 19 computed with the original GDR tide correc- 
Cycle 18

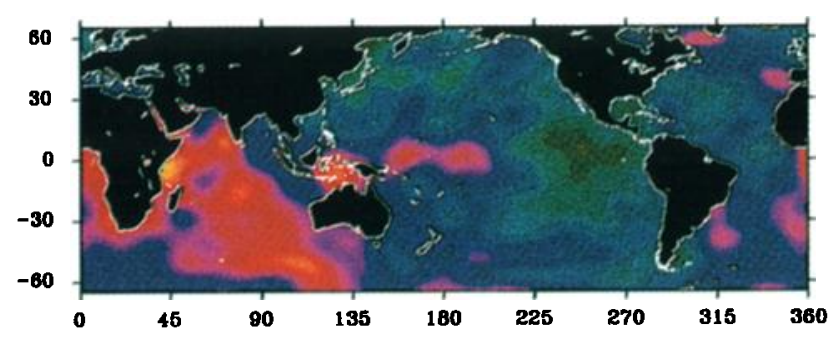

Cycle 16 with CSR tide model

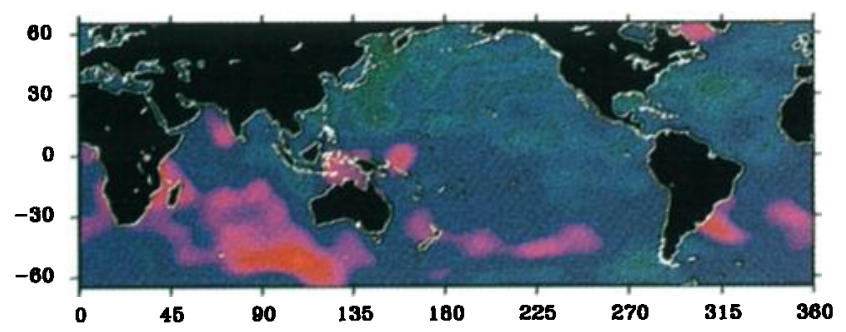

Cycle 19

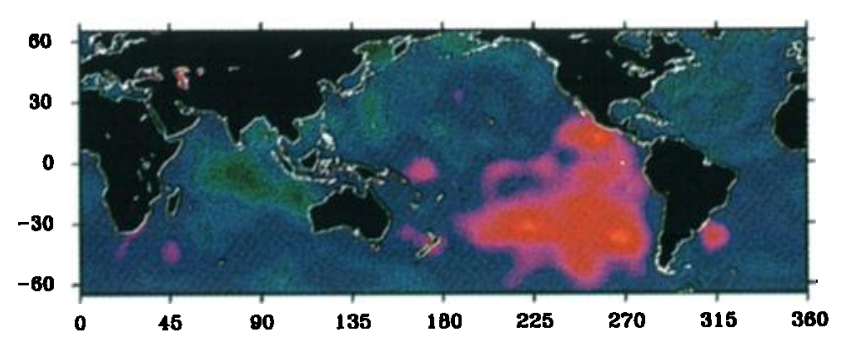

Cycle 19 with CSR tide model

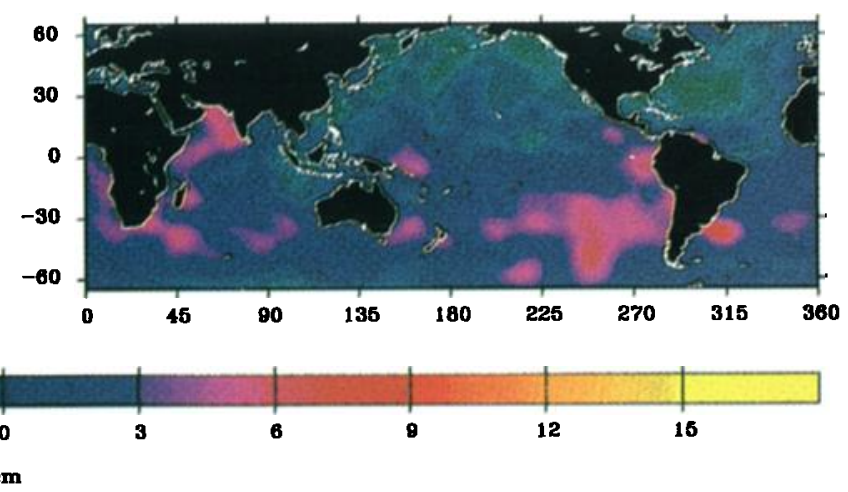

Plate 1. Changes in dynamic ocean topography due to corrections of the ocean tide model. The left column shows topography anomalies computed using the Cartwright and Ray model packed with the GDR for cycles 16 and 19 . The right column shows the same cycles after a corrected tide model was computed from a year of TOPEX altimeter data.

tion. Over a period of $\mathbf{3 0}$ days the eastern Pacific appears to rise by approximately $16 \mathrm{~cm}$, while the Indian Ocean drops by a similar amount. An examination of all the cycles indicated that this pattern repeats approximately every 60 days, which is close to the tidal aliasing period for the $\mathbf{M}_{2}$ tide. To determine if this error was due to errors in the tide model, a correction to the Cartwright and Ray tide model was estimated by gridding the altimeter residuals into $3^{\circ} \times 3^{\circ}$ bins and solving for corrections to the semidiurnal $\left(M_{2}, S_{2}, N_{2}, K_{2}\right)$ and diurnal $\left(K_{1}, O_{1}, P_{1}, Q_{1}\right)$ constituents, along with three long-period constituents $\left(\mathrm{M}_{\mathrm{f}}, \mathrm{M}_{\mathrm{m}}, \mathrm{S}_{\mathrm{sa}}\right)[\mathrm{Ma}$ et $a l .$, this issue]. The right column of Plate 1 shows the topography anomalies for cycles 16 and 19 after the tide model has been corrected. The large 60 -day variations in the left column figures is significantly reduced in the corrected results for cycles 16 and 19 and in all subsequent 10-day topographies.

With the corrections for the ocean tide model and the improved orbit accuracy, the errors in the marine geoid are the limiting error source in studying the dynamic ocean topography. This study used the JGM-2 gravity field model as the reference geoid model for dynamic ocean topography measurements. This model was developed for the stringent orbit accuracy required for the TOPEX/POSEIDON mission and contains spherical harmonics complete to degree and order 70 [Nerem et al., this issue]. The accuracy of the geoid over the oceans is estimated to be around 15 $\mathrm{cm}$ at wavelengths greater than $1600 \mathrm{~km}$.

Following an approach similar to Nerem et al. [1990], the wavelength at which the mean sea surface topography and the marine geoid are separable was determined by comparing the degree variance of the topography and the degree error variance of the reference geoid. However, since the reference geoid errors over the land/polar areas are much larger than errors over the oceanic areas and since the sea surface topography has zero values over the land/polar areas, the direct comparison of the degree variances can underestimate the maximum degree at which the power of the geoid error begins to exceed the power of the residual mean sea surface. To alleviate this problem, the oceanic contribution of the predicted geoid undulation errors to the geoid error degree variance was rigorously evaluated [Kim et al., 1993] using the JGM-2 geopotential error covariance. Figure 1 shows the degree variance of mean sea surface topography, as determined by the TOPEX altimeter data and the degree error variance of the JGM-2 geoid over the ocean. The oceanic geoid error degree variance of the JGM-2 model exceeds the degree variance of the residual mean sea surface around degree 25 , suggesting that higher order surface topography models will be influenced by geoid error aliasing.

\section{Mean Dynamic Ocean Topography}

When the dynamic ocean topography is determined from data collected over an extended time period, short-period variations are averaged, and the resulting averaged surface should represent the topography due to the mean geostrophic ocean currents. In this treatment the ocean topography observations from September 1992 to September 1993 , cycles $1-36$, were averaged into $1^{\circ} \times 1^{\circ}$ grids and then filtered with a $25 \times 25$ surface spherical harmonic representation to examine features with wavelengths $>1600 \mathrm{~km}$. An a priori covariance power rule determined from the Levitus 


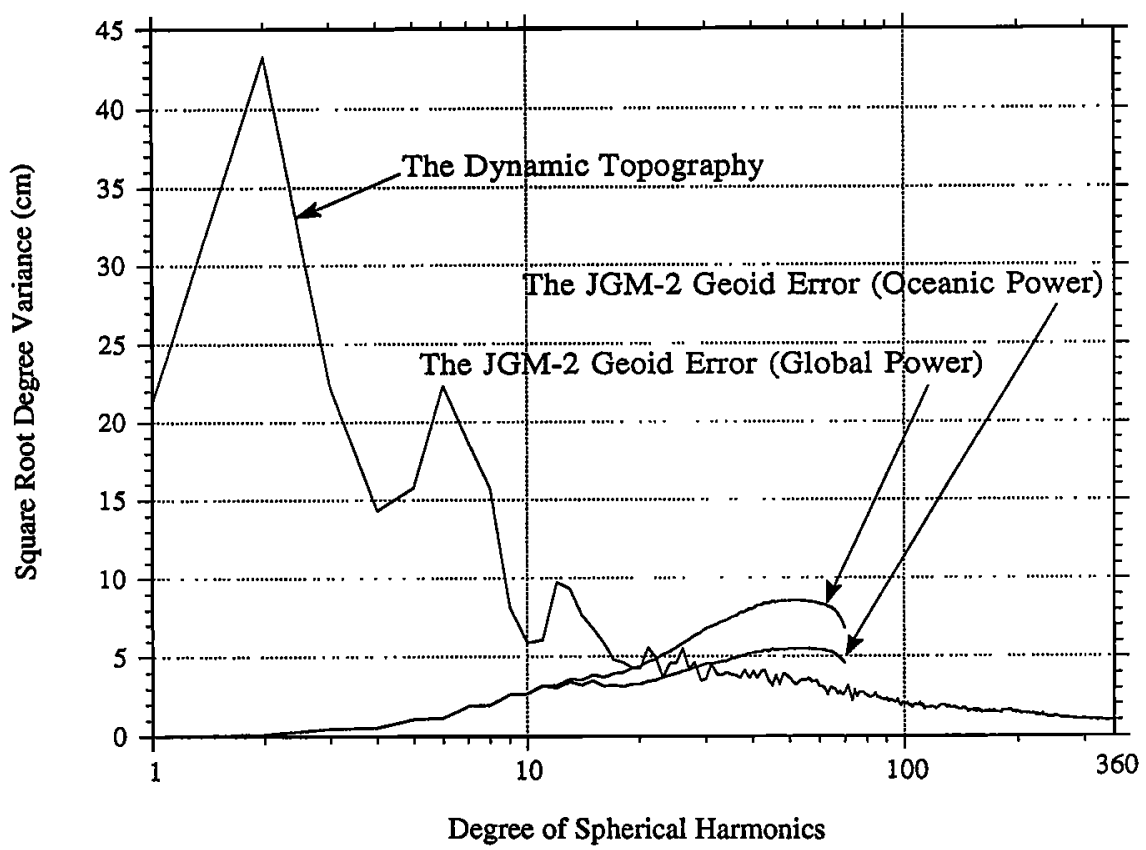

Figure 1. Spectral power comparison between the residual mean sea surface and the predicted JGM-2 geoid error.

hydrographic data was used to reduce the effect of the nonglobal distribution of the altimeter data [Nerem et al., 1990]. Plate 2 shows the 1-year mean dynamic ocean topography referenced to the JGM-2 geoid, as observed by TOPEX/POSEIDON during the period from September 1992 through September 1993. The altimeter data used to generate this surface were corrected for tide error with preliminary tide corrections computed from TOPEX/ POSEIDON GDR data [ $\mathrm{Ma}$ et $\mathrm{al}$., this issue], but this topography is virtually identical to the topography determined using the original tide corrections, since the effect of the tides, over a 1-year period, will be averaged to nearly zero. However, for the timevarying sea surface topographies described in the following sec- tion, the use of an improved tide model was found to be essential. The topography has been corrected for the permanent (zerofrequency) luni-solar tides [Nerem et al., 1990].

Geostrophic currents will flow along lines of constant ocean topography so that highs are to the right in the northern hemisphere and to the left in the southern hemisphere. Examining Plate 2, it can seen that the Antarctic Circumpolar Current is very well defined, as are the strong western boundary currents. The Gulf Stream and the subtropic and subpolar gyres are evident features in the North Atlantic. The Pacific region shows the Kuroshio Current, along with major highs near the equator in both the northern and southern hemispheres. The Falklands Current off

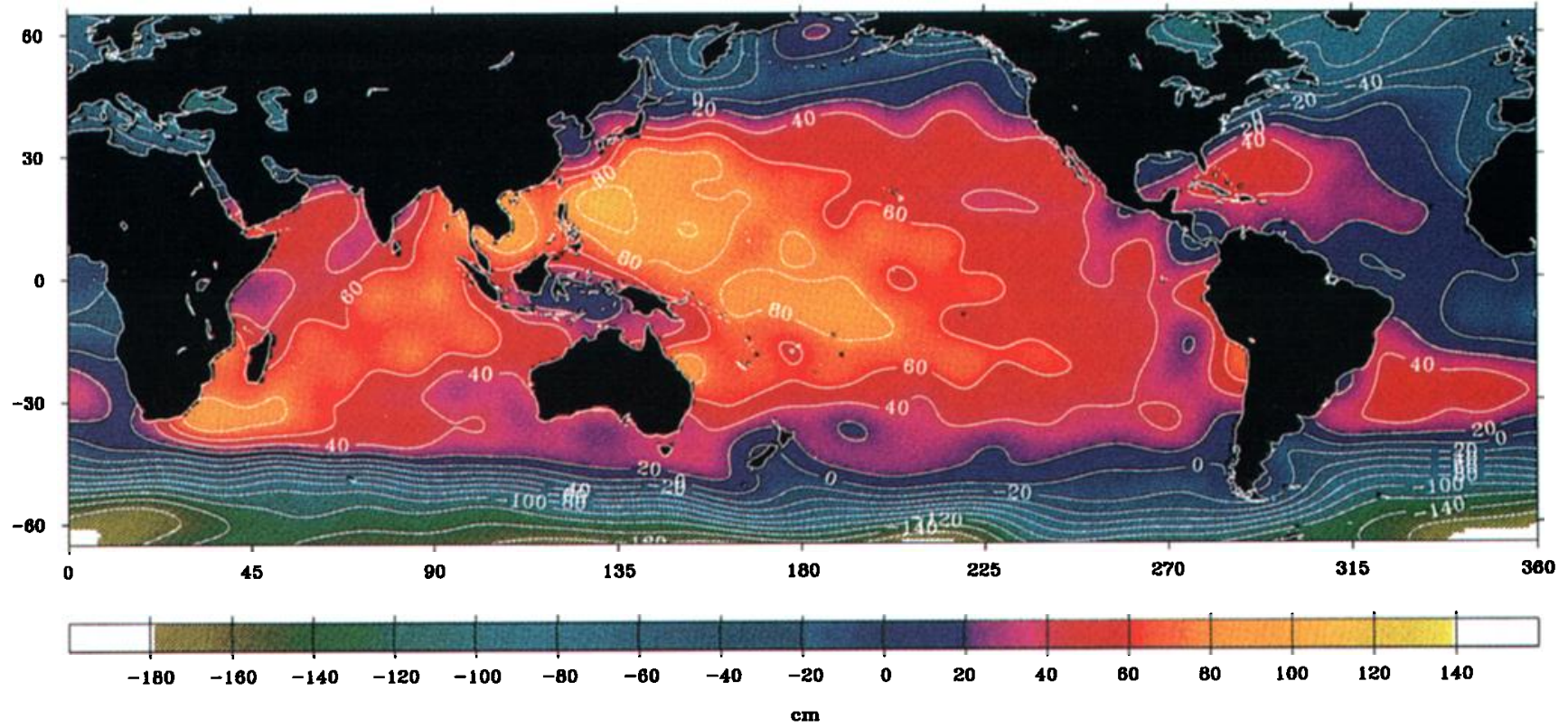

Plate 2. Mean dynamic ocean topography referenced to JGM-2 geoid, computed from TOPEX altimeter data from cycles 1 to 36 . 
OSU91A

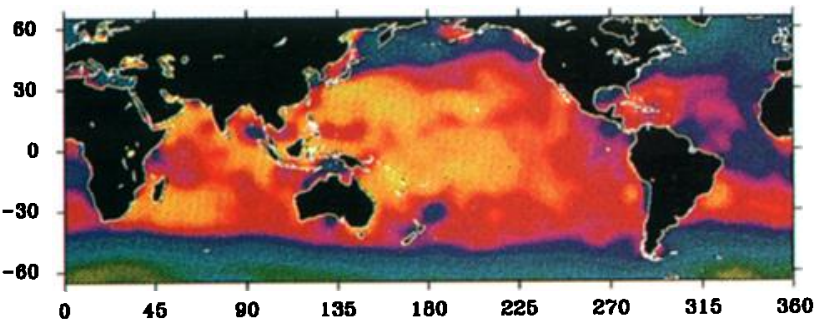

0SU91A/JGN-2

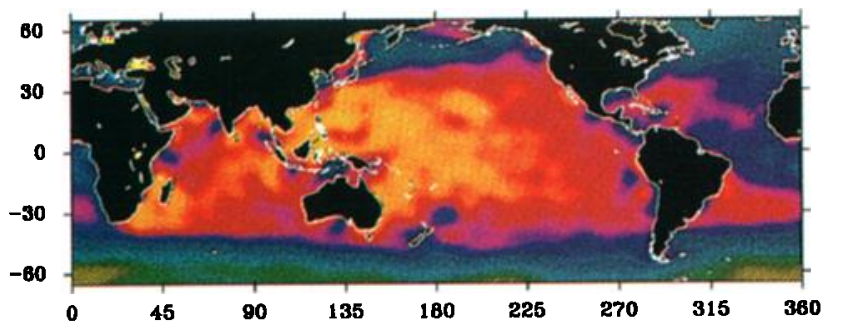

JGM-2

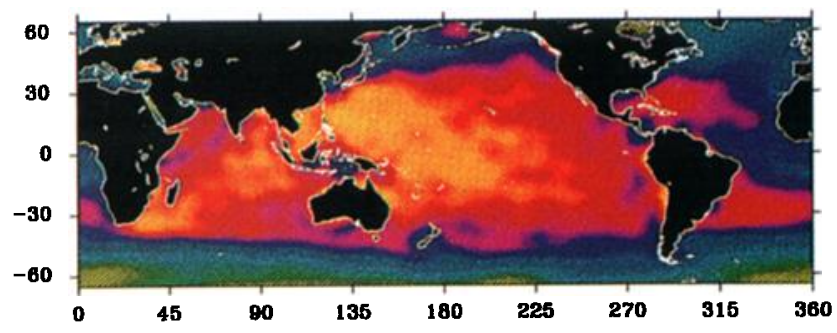

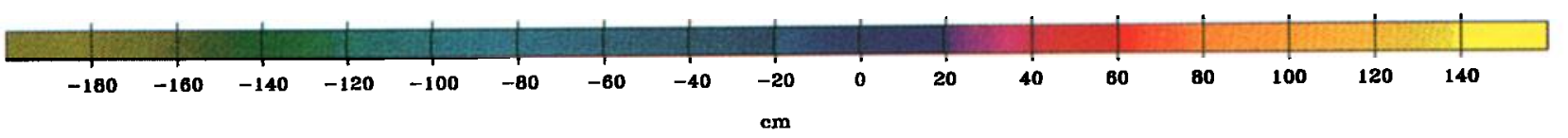

Plate 3. Dynamic ocean topography for cycle 35 of TOPEX/POSEIDON, referenced to four geoid models: OSU91A, JGM-2/OSU91 A hybrid, JGM-2, and JGM-3.

the southeast coast of South America is also evident. However, the feature associated with the trough in the western Pacific between $3^{\circ}$ and $8^{\circ} \mathrm{N}$ caused by the strong eastward flowing North Equatorial Countercurrent (NECC) is not evident. This feature is visible in the dynamic topography computed by Levitus [1982] from hydrographic data and is expected to be visible in the altimeter data, unless the current is behaving anomalously during this time. Assuming that it does exist during this period, there are at least two reasons why the trough may not be observed by the altimeter. The altimeter data could be in error, or the geoid could be in error in this region. By examining dynamic ocean topography referenced to various geoid models, the influence of the geoid mode on the results can be assessed.

Plate 3 shows dynamic ocean topography for repeat cycle 35 , determined by using four contemporary geoid models. These models are the JGM-2 model [Nerem et al., this issue], the OSU91A model [Rapp et al., 1991], which was placed on the GDR, a model composed of degrees and orders up to 70 from the JGM-2 gravity model and higher order terms from OSU91A, and the recently developed JGM-3 model [Tapley et al., 1994]. Consistent with the previous discussion, all the topographies shown used the same sea surface height measurements and were filtered with a spherical harmonics model complete to degree and order 25. To test the effect of the approach used to determine the average sea surface topography, a different short-wavelength filter, which is described in the following section, was also applied to these data. At the $1600-\mathrm{km}$ wavelength, the results achieved were identical with the long-wavelength spherical harmonic filter, suggesting that the spherical harmonic filter will accurately define the broad-scale circulation features that are present in the data. It also indicates that the absence of the NECC trough in the ocean topog- raphy determined using the JGM-2 geoid model is not due to the use of the spherical harmonic filter.

Returning to the maps in Plate 3, one sees a depression in the area of the NECC in the OSU91A topography and in the JGM-3 topography, although the feature does differ between the two. The JGM-2 topographies show little or no depression in the area, which does not agree with observations by Wyrtki [1974] that the depth of the NECC trough is greatest during this time period. It is clear that these four topography solutions have significant differences, and the differences are due to the geoid model to which they are referenced, since all surfaces were determined with the same sea surface and analysis technique.

Plate 4 shows differences after the Levitus topography has been subtracted from the four TOPEX topographies, with a mean removed. Data below $50^{\circ} \mathrm{S}$ were removed because the Levitus topography is not well determined in this region, due to limited hydrographic data. The global RMS difference between the Levitus topography and the four different TOPEX-defined sea surface topographies are shown in Table 1 . Overall, the dynamic ocean topography referenced to the JGM-3 geoid shows the closest agreement with the Levitus topography, with an RMS difference of only $18 \mathrm{~cm}$. However, regional differences can still be as high as $30 \mathrm{~cm}$, but because these are common to all the maps, these differences may be due to errors in the Levitus topography. Wunsch [1981] has shown that the depth assumed for the level of zero motion can introduce errors as large as $20 \mathrm{~cm}$ into the recovered topography.

Looking at the equatorial Pacific, large differences can be seen around the NECC trough in the dynamic topographies referenced to the JGM-2 and JGM-2/OSU91A hybrid geoids. It is also evident that the OSU91A topography is actually lower than Levitus 

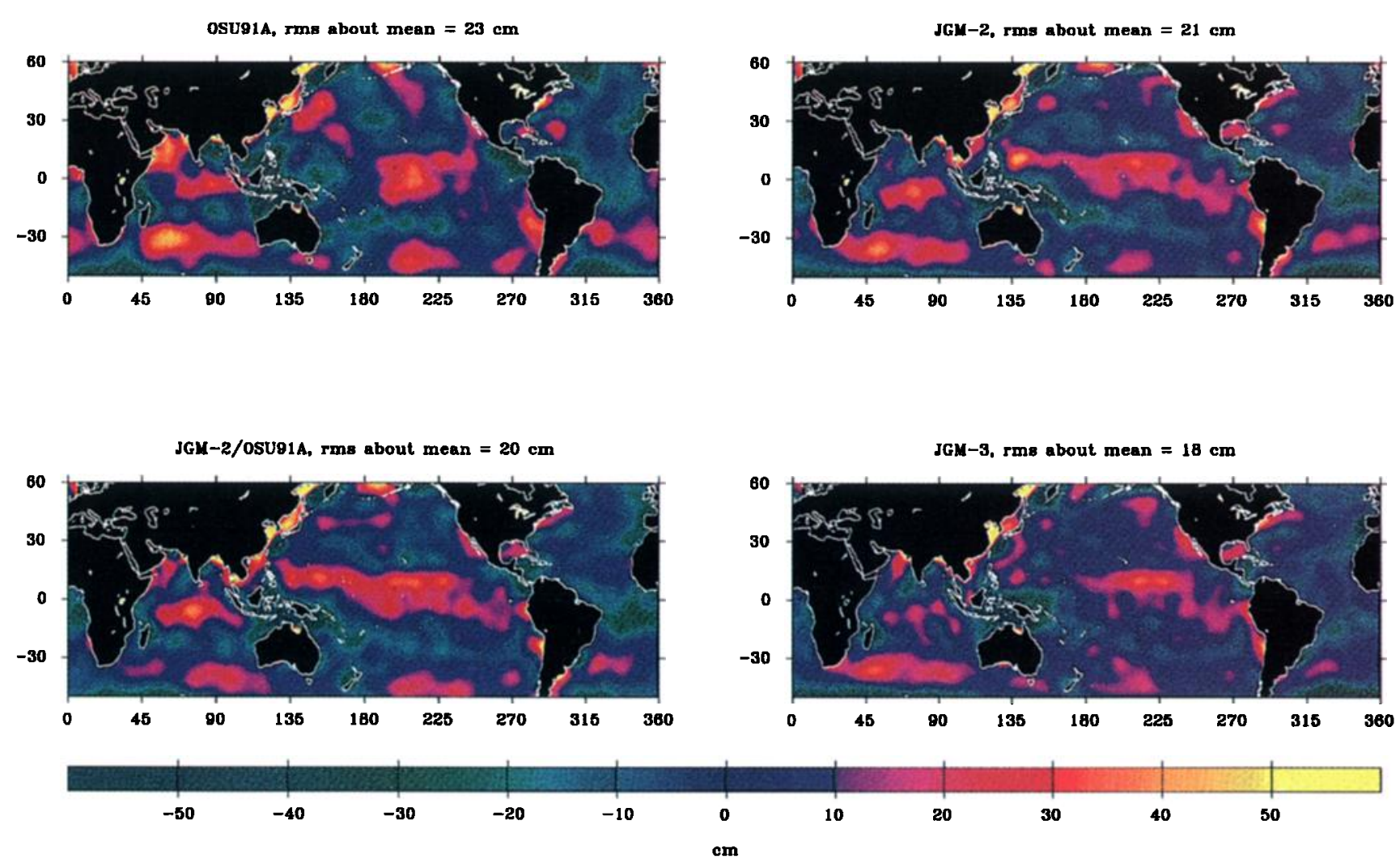

Plate 4. The difference between the dynamic ocean topography maps in Plate 3 with a 70 -year average topography computed by Levitus.

in the eastern equatorial Pacific, while the other topographies are higher. Recall that an El Niño event was occurring at this time, which should bring higher than normal sea levels in this region. The TOPEX-measured ocean topography referenced to the OSU91A geoid in this region is inconsistent with this conjecture.

This analysis illustrates the generally accepted conclusion that the main problem in determining absolute dynamic ocean topography from satellite altimetry is error in the reference geoid. Current accuracy assessments of geoid models are of the order of $10-15 \mathrm{~cm}$ over the ocean for terms up to degree and order 25 (or wavelengths of the order of $1600 \mathrm{~km}$ or greater). However, this means that local errors can be 2 or 3 times that value. These errors go directly into the dynamic ocean topography measurement and hence the computed ocean circulation. One way to minimize the effect of geoid error is to focus on variations in the dynamic ocean topography.

\section{Variations in Dynamic Ocean Topography}

Global sea level variation maps were created by first computing the residual

Table 1. TOPEX/POSEIDON Ocean Topography Comparison With Levitus Topography for Cycle 35

\begin{tabular}{lcc}
\hline Geoid Model & Mean Difference, cm & RMS About Mean, cm \\
\hline OSU91A & -6.0 & 23.3 \\
JGM-2 & -5.9 & 21.1 \\
JGM-2/OSU91A & -9.8 & 20.2 \\
JGM-3 & -5.0 & 17.8 \\
\hline
\end{tabular}

$$
\Delta h=h_{\zeta}-\left\langle h_{\zeta}\right\rangle
$$

where $h_{\zeta}$ is sea surface topography measurement, and $\left\langle h_{\zeta}\right\rangle$ is the reference or mean ocean topography, which is defined as the time average topography determined from the first year of TOPEX/POSEIDON data. The residual $\Delta h$ will contain information about the sea level variation, as well as the effects of geoid error, mean ocean topography error, orbit error, tide model error, as well as error in the instrument corrections. The global residuals for most TOPEX/POSEIDON repeat cycles, after using the TOPEX altimeter data to determine a mean ocean topography, have a root-mean-square (RMS) value between 18 and $19 \mathrm{~cm}$.

As noted previously, preliminary analysis of these residuals indicated that a significant portion of the signal was due to ocean tide model error. Since the tide variations have components with known and distinct frequencies, it is relatively straightforward to grid the residuals into small bins $\left(3^{\circ} \times 3^{\circ}\right)$ and estimate tide corrections for each bin, while simultaneously estimating yearlong biases which would absorb the main portions of the geoid and dynamic ocean topography error. The true ocean variation signal is not affected, and any remaining errors should be much smaller than this signal. As discussed previously, a solution for a tide model correction was estimated from residuals obtained from TOPEX GDR data for repeat cycles 1-19, 21-30, 32-36 [Ma et $a l$. , this issue]. When the estimated corrections were applied to the repeat-track residuals, the RMS value was reduced from 19 $\mathrm{cm}$ to $12-14 \mathrm{~cm}$. The RMS of the corrections to the Cartwright and Ray tide model varies from 5 to $7 \mathrm{~cm}$ over cycles 1-36.

After removing a mean annual topography and applying the corrections to the tide model, the residuals contains information which is predominantly related to sea level anomalies, or variations about a mean sea surface topography. To better observe the ocean topography variations, the corrected residuals were first 
averaged into $1^{\circ} \times 1^{\circ}$ grids. Next, a short wavelength filter was applied to these grids to smooth the data and reduce the noise without distorting the original data. The filter examined the $n$ grid points in a $7^{\circ} \times 7^{\circ}$ box centered on the point, $h_{c}$, for which a smoothed value was desired. The magnitude of $h_{c}$ was determined as the weighted average of the data in the block of grids by

$$
h_{c}=\sum_{i=1}^{n} w_{i} \times h_{i} / \sum_{i=1}^{n} w_{i}
$$

where $w_{i}$ is a weight assigned by a Gaussian function

$$
w_{i}=\exp \left(-r / 1^{\circ}\right)
$$

where $r$ is the "radius" from the center point to the data point. Thus if there is a datum at the center grid, its weight would be 1 ; a datum at the edge of the block would have a weight of 0.05 . Finally, a value of "no data" was assigned if the sum of the weights was less than 0.2 .

The following sections examine ocean topography variations on a global and regional scale and compare the variations observed by TOPEX/POSEIDON with variations expected due to oceanographic processes.

\section{Variations in Seasonal Dynamic Ocean Topography}

Ocean topography anomalies were averaged into 3-month maps corresponding to the seasons, as defined in the northern hemisphere (see Plate 5). The anomalies are mostly positive in the north and negative in the south during the northern hemisphere fall and summer. The trend reverses during the spring and winter, although the extent of the high anomalies in the southern hemi- sphere is not as great as it is 6 months later in the north. Wyrtki [1974] observed similar seasonal variations in tide gauge data, attributable to the annual heating/cooling cycle and changes in the steric sea level. In particular, the North Equatorial Ridge at approximately $20^{\circ} \mathrm{N}$ is higher than average in the summer and lower than average in the winter. This is reflected in the variations measured by TOPEX/POSEIDON. During the summer of 1993 there is a band of high anomalies in the western Pacific, centered about $18^{\circ} \mathrm{N}$. Six months earlier, in winter, the peak values in the same area were over $10 \mathrm{~cm}$ lower. Note also the strong annual variation in the Indian Ocean associated with the monsoon cycle.

\section{Variations in the Indian Ocean}

During the northern winter, air over southeast Asia is cooler and denser than air over the Indian Ocean. This results in an atmospheric pressure imbalance, and the resulting pressure gradient leads to a northeasterly wind (the North-East Monsoon) which blows from the continent toward the ocean. As the year progresses, the air over the land warms until the pressure gradient reverses, and warm, moist air (the South-West Monsoon) blows from the ocean to the continent.

These shifting winds influence the current system in the Indian Ocean, in particular the Somali Current off the east coast of Africa. During the North-East Monsoon, the Somali Current is a moderate current flowing to the south. However, during the South-West Monsoon, the Somali Current changes direction and becomes a strong boundary current. There are other variations in the Indian Ocean circulation during the year, that is, the reversal of the gyre in the Bay of Bengal, and the reversal of the equatorial current from northem winter to northern summer. Thus the
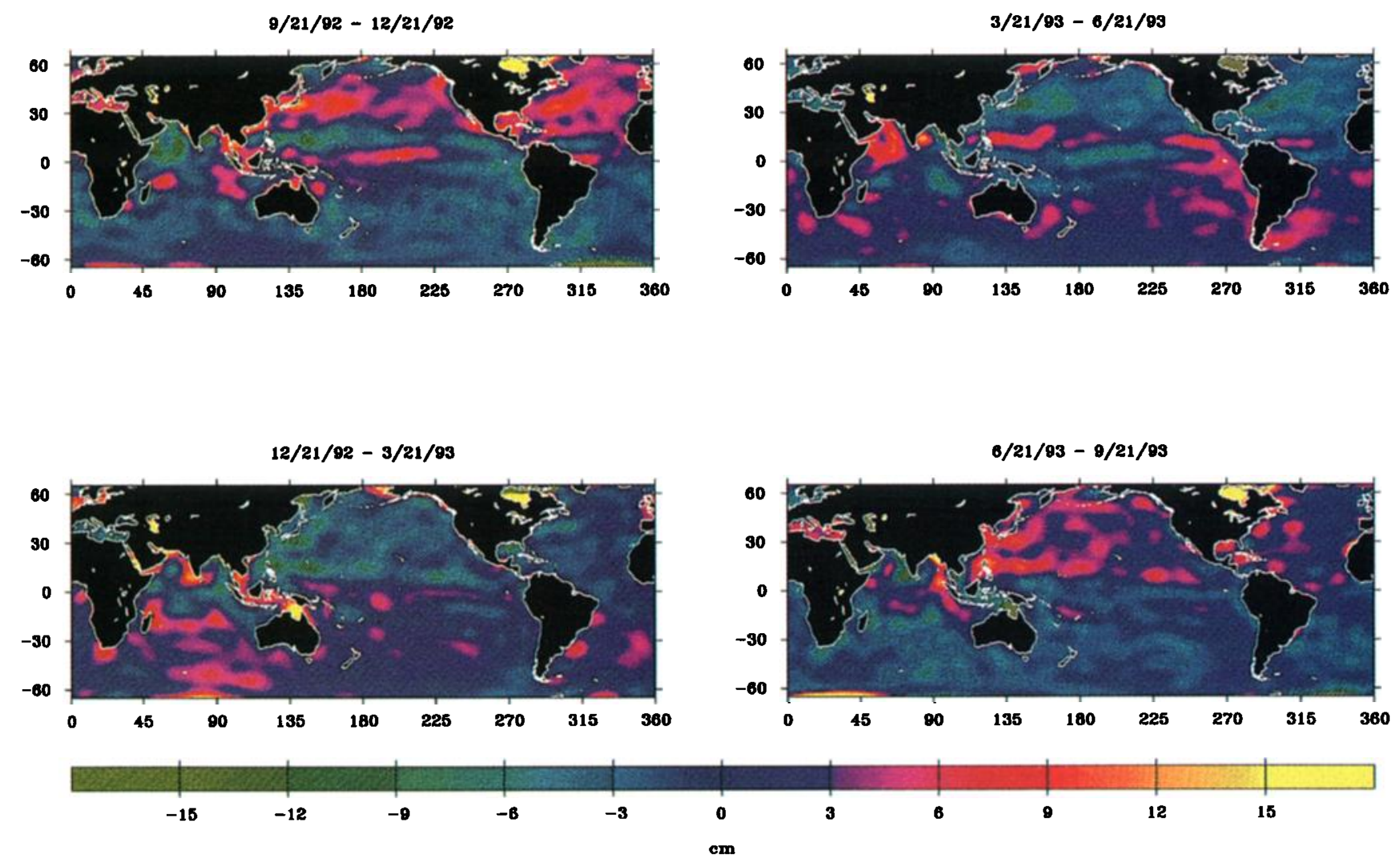

Plate 5. Seasonal dynamic ocean topography anomalies from TOPEX/POSEIDON altimetry. The high anomalies in the northern hemisphere during the summer and fall are associated with the annual heating cycle of the oceans. 

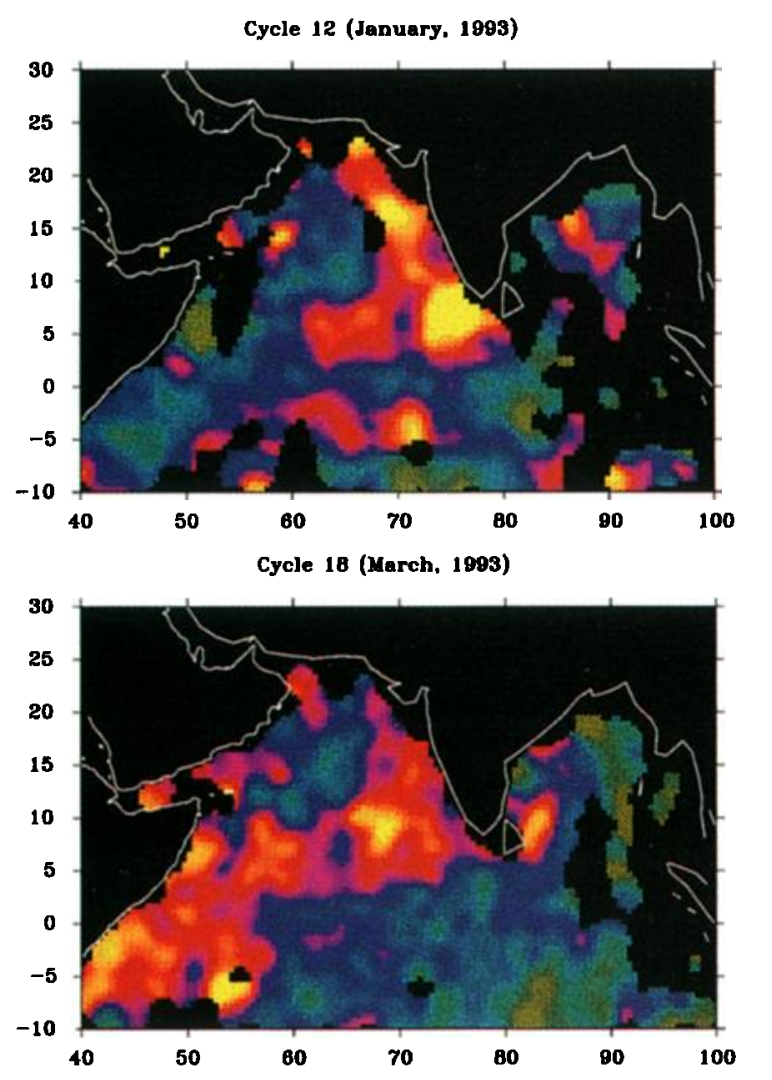
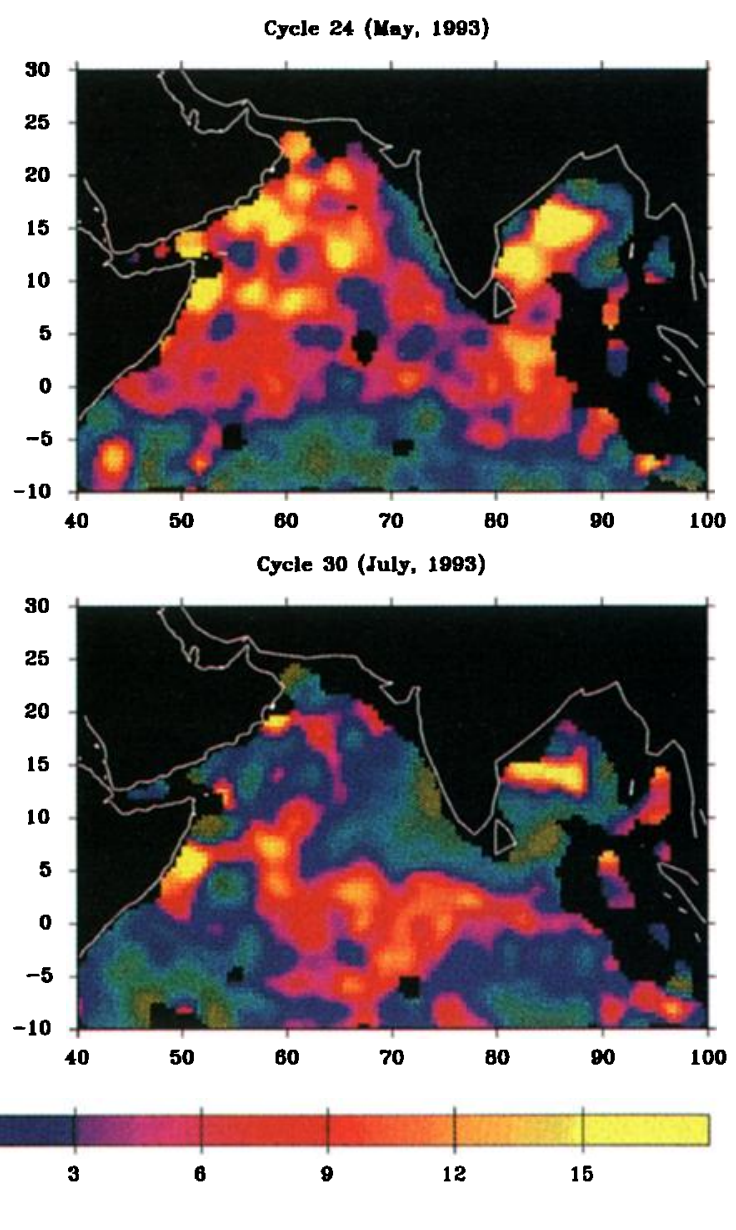

Plate 6. Dynamic ocean topography anomalies in the Indian Ocean as measured by TOPEX/POSEIDON during January, March, May, and July of 1993.

current system in the Indian Ocean has a strong seasonal variability. This variability is clearly evident in the 10-day dynamic ocean topography anomaly maps, of which four are represented in Plate 6. These maps represent periods in January, March, May, and July of 1993 and were smoothed with the short-wavelength filter described previously. The blacked out regions in the maps indicate areas where there were not adequate data, such as the unprocessed POSEIDON altimeter data from the early repeat cycles.

In the region south of India, where the current varies from the westward flowing North Equatorial Current to the eastward flowing South-West Monsoon Current in 6 months, the sea surface topography changes from a large positive to a large negative anomaly in the same amount of time. Large anomaly changes are also present in the Somali Current region and in the Bay of Bengal. These changes are consistent with variations in the current system caused by the changing monsoon winds.

\section{Pacific Equatorial Wave}

The most demanding task for the altimeter data is to observe the spatial extent of episodic features which change significantly from one 10-day cycle to the next. An example of such a feature is the interannual event known as El Niño. A small El Niño event began in mid-1991, reached its maximum peak near the beginning of 1992, and appeared to be losing strength that same summer, near the time TOPEX/POSEIDON was launched. However, on December 21, 1992, oceanographers in the Pacific observed an anomalous wind blowing in the opposite direction from the normal trade winds, that is, from west to east. The wind burst lasted for 2 weeks, with sustained winds up to $16 \mathrm{~m} / \mathrm{s}$. Two more wind bursts followed the first one, each one lasting for approximately the same 2-week period.

This type of event is believed to be a precursor to most El Niño events, and in fact, this did lead to a strengthening of the $1992 \mathrm{El}$ Niño which had been decaying. The abrupt change in the wind direction causes a change in the upper ocean, a depression in the thermocline along with a rise in the ocean surface, which propagates eastward along the equator as a Kelvin wave [Philander, 1990]. By this process the Kelvin wave deepens the thermocline in the eastern Pacific and also causes significantly higher sea levels of the order of 5 to $10 \mathrm{~cm}$.

If the previous assertion on the accuracy of the TOPEX/ POSEIDON height measurement is correct, the propagation of the Kelvin wave should be visible in the sea level anomaly maps. Plates 7a and $7 \mathrm{~b}$ show sections of the global maps for cycles 10 through 22, excluding cycle 20. Again, the blacked out regions correspond to areas observed mostly by the POSEIDON altimeter. These sections cover an area of the tropical Pacific from $150^{\circ} \mathrm{E}$ to $290^{\circ} \mathrm{E}$ longitude and $20^{\circ} \mathrm{S}$ to $20^{\circ} \mathrm{N}$ latitude. Examining the time series and noting that each cycle comprises $\mathbf{1 0}$ days of data, the high anomalies can be seen clearly, propagating from west to east from cycle 11 to cycle 15 along the equatorial wave guide.

The start time of cycle 11 is only 10 days after the first recorded anomalous winds, which occurred near the beginning of cycle 10 . In the cycle 11 map, note a very high ocean topography anomaly 
Cycle 10

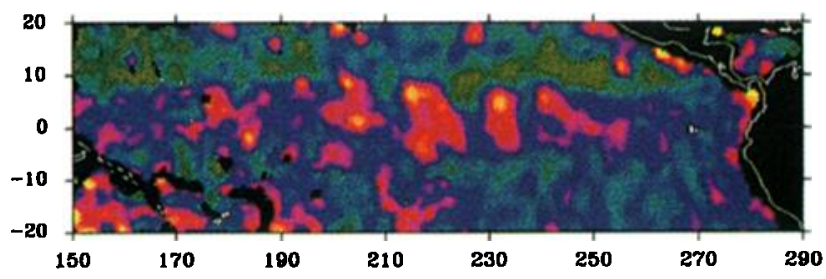

Cycle 11

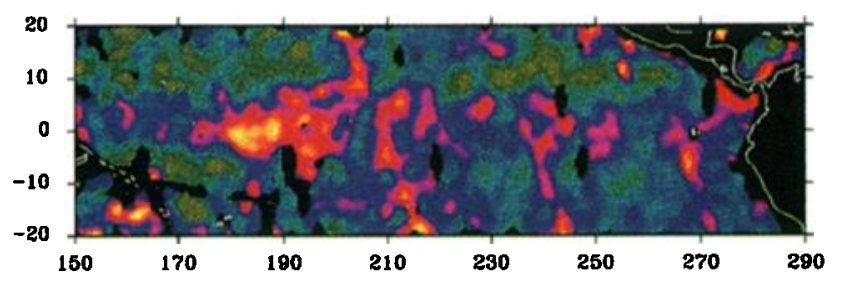

Cycle 12

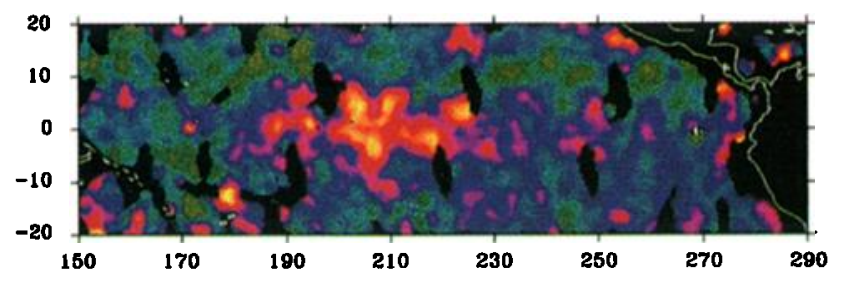

Cycle 13

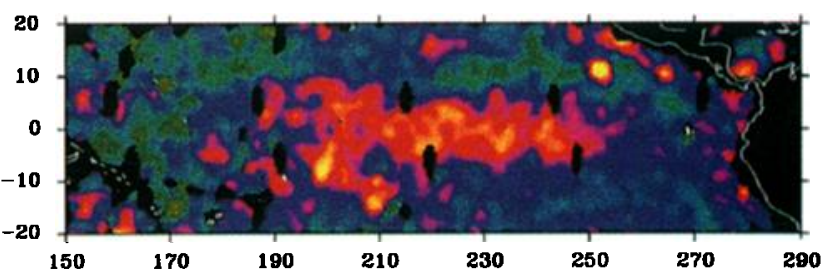

Cycle 14

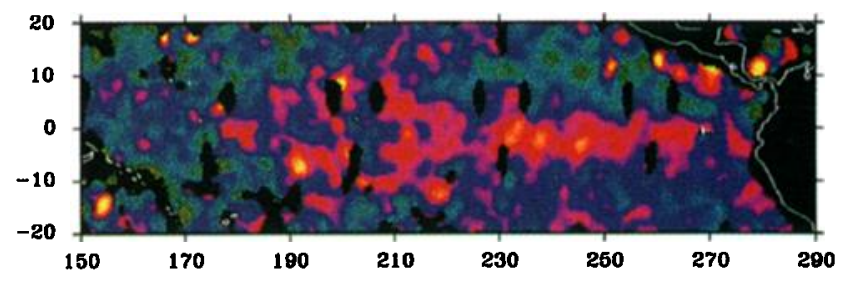

Cycle 15

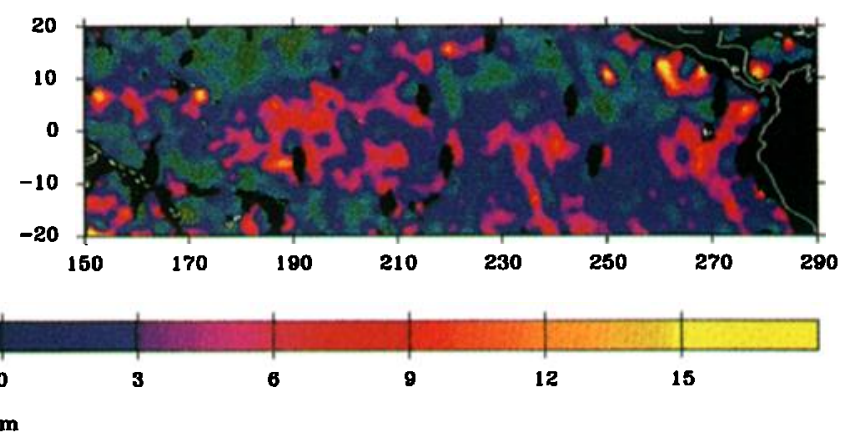

Plate 7a. Dynamic ocean topography anomalies in the tropical Pacific Ocean as measured by TOPEX/POSEIDON from December 21, 1992, through February 18, 1993 (cycles 10-15). Note the high anomalies associated with a Kelvin wave moving eastward along the equator.

centered on the equator at approximately $180^{\circ} \mathrm{E}$ longitude. Ten days later, in cycle 12 , the highest equatorial anomaly is centered at $200^{\circ} \mathrm{E}$. If this high topography anomaly is associated with the Kelvin wave, then it has traveled with a speed of approximately $2.6 \mathrm{~m} / \mathrm{s}$. The theoretical phase speed for a free Kelvin wave in the equatorial Pacific is predicted to be between 2.2 and $3 \mathrm{~m} / \mathrm{s}$. Wunsch and Gill [1976] report that a typical value for an equatorial Kelvin wave is $2.8 \mathrm{~m} / \mathrm{s}$, and Miller el al. [1988] used Geosat altimeter data to observe a Kelvin wave with a phase speed of 2.8 $\mathrm{m} / \mathrm{s}$ during the 1986-1987 El Niño.

By cycle 13 the high topography anomalies associated with the Kelvin wave have spread out over $4000 \mathrm{~km}$, centered at about $230^{\circ} \mathrm{E}$. In cycle 14 the center of the anomaly band is at about $250^{\circ} \mathrm{E}$. The speed of the center of this anomaly band is also about $2.6 \mathrm{~m} / \mathrm{s}$ and again is consistent with the theoretical and observed speed of Kelvin waves. The eastward flowing high topography anomalies appear to reach the coast of South America in cycle 15, and starting in cycle 18 the sea level in the eastern equatorial Pacific rises dramatically. It should be noted that the cycle 16 and cycle 17 maps actually show lower sea levels in the region than in cycle 15 as the trough of the Kelvin wave arrives. This drop has also been observed in tide gauge data, as is discussed later.

The movement of the high topography anomalies was also examined in closer detail at the equator. The ocean topography variation residuals for every day were averaged into bins $4^{\circ}$ in longitude by $2^{\circ}$ in latitude, straddling the equator. The data were then filtered with a Fourier series to $n=15$ which fit the data to less than $4 \mathrm{~cm}$ RMS in each bin. The time of the maximum positive anomaly was computed in each bin from the filtered data, and the longitude of the maximum is plotted as a function of time in Figure 2. A line was fit through the data points using a least squares method. The slope of the line is $2.3 \%$ day with a scatter of less than $3 \%$. This corresponds to a wave speed of $3 \pm 0.1 \mathrm{~m} / \mathrm{s}$. This is again consistent with the previous assessment. The highest anomaly occurred at longitude $168^{\circ} \mathrm{E}$ on December 27, 1992, approximately 6 days after the change in the trade winds was observed. Forty-six days later, during repeat cycle 15 , the highest anomaly occurred at longitude $272^{\circ} \mathrm{E}$, off the coast of South America. Thus it appears that the Kelvin wave reached the South American coast on or about February 11, 1993.

The interpretation of the sequence of events shown in Plate 7 is confirmed by tide gauge data from sites on Christmas Island in the western Pacific and Baltra in the Galapagos Islands in the eastern Pacific. A constant bias between the tide gauge data and altimeter data due to different reference systems has been removed from the tide gauge data. The results from the globally determined 10-day averaged dynamic ocean topographies from TOPEX, evaluated at the tide gauge locations, and the tide gauge measurements in Figure 3 show a $10-\mathrm{cm}$ amplitude wave propagating from the westem Pacific to the eastern Pacific, which is consistent with the previous discussion. The sea level drops at Christmas Island at about the same time it rises at Baltra, consistent with the change in thermocline depth associated with an El Niño event. As mentioned previously, cycle 16 in Figure 3 shows a $10-\mathrm{cm}$ drop in the sea sur- 

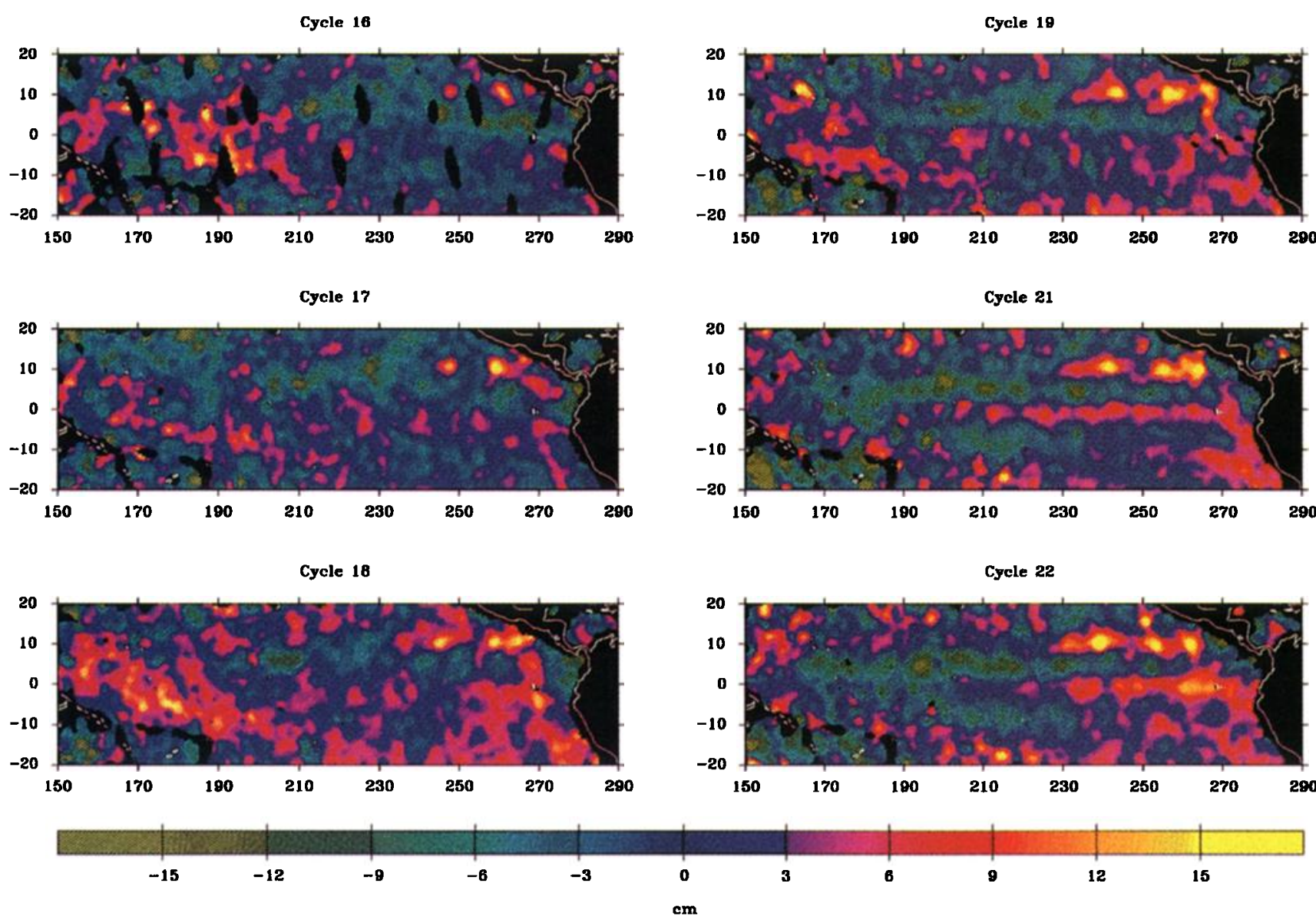

Plate 7b. Dynamic ocean topography anomalies in the tropical Pacific Ocean as measured by TOPEX/POSEIDON from February 18, 1993, through April 29, 1993 (cycles 16-22). Note the high anomalies centered at $10^{\circ} \mathrm{N}$ latitude which are moving slowly westward.

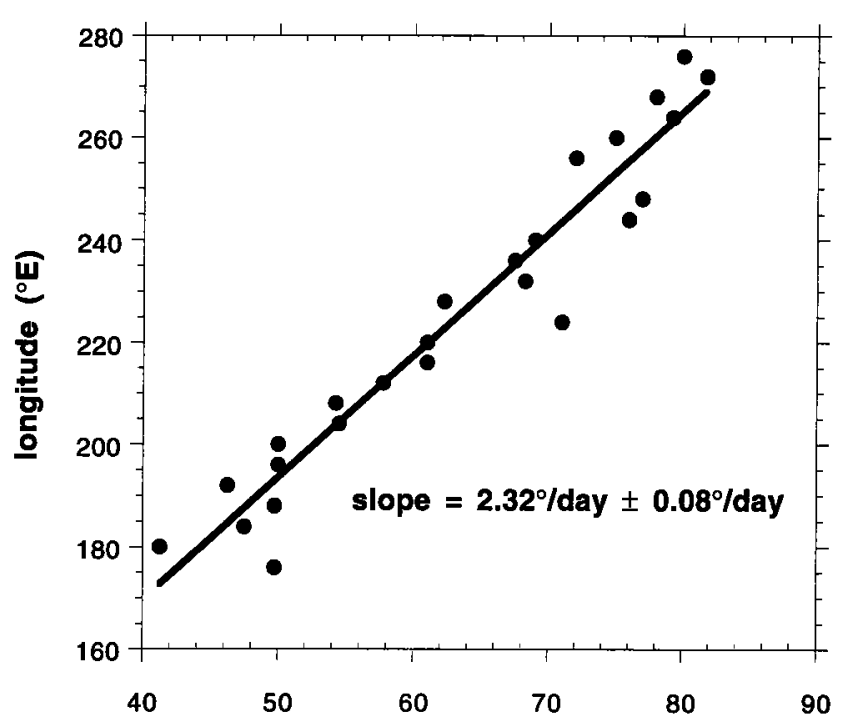

time of maximum height (days past start of cycle 7)

Figure 2. Time of maximum anomaly height versus longitude from filtered topography anomalies along the equator at 4 degree longitude intervals. The slope of the line is $2.32 \%$ day, with a scatter of about $3 \%$. This indicates that a high anomaly was propagating across the equator with a speed of approximately $3 \mathrm{~m} / \mathrm{s}$. face over the previous cycle and the following cycle as the Kelvin wave trough reaches the area. This drop is confirmed by the tide gauge measurement at Baltra, confirming that it is a true change in the sea level and not an anomalous measurement by TOPEX POSEIDON.

Finally, another region of intense high anomalies is visible in a band around $11^{\circ} \mathrm{N}$ latitude, starting at $260^{\circ} \mathrm{E}$, as shown in Plate 8 . These anomalies are all moving westward at approximately the same speed and could represent mesoscale eddies. An analysis of the movement of the center of the highest points through cycle 36 indicates they are moving westward with a velocity of approximately $18 \mathrm{~cm} / \mathrm{s}$. Giese et al. [this issue] also discusses these eddies and notes that they are correlated with wind bursts off the Central American coast. The results in Plate 8 indicate the ability of the dual-frequency TOPEX altimeter measurements to track the temporal change in mesoscale features with amplitudes less than $10 \mathrm{~cm}$ on timescales of 10 days.

\section{Comparison Against in Situ Tide Gauge Data}

In addition to the specific examples shown in Figure 3, island tide gauge data provide a valuable tie to compare satellite altimeter data to observations made at the surface of the ocean. Sea level variation data from 19 tide gauge sites from the World Ocean Circulation Experiment (WOCE) database managed by the Integrated Global Ocean Services System (G. Mitchum, personal communication, 1993) were compared with long-wavelength 


\section{Christmas $\left(1^{\circ} 59^{\prime} \mathrm{N}, 157^{\circ} 29^{\prime} \mathrm{W}\right)$}
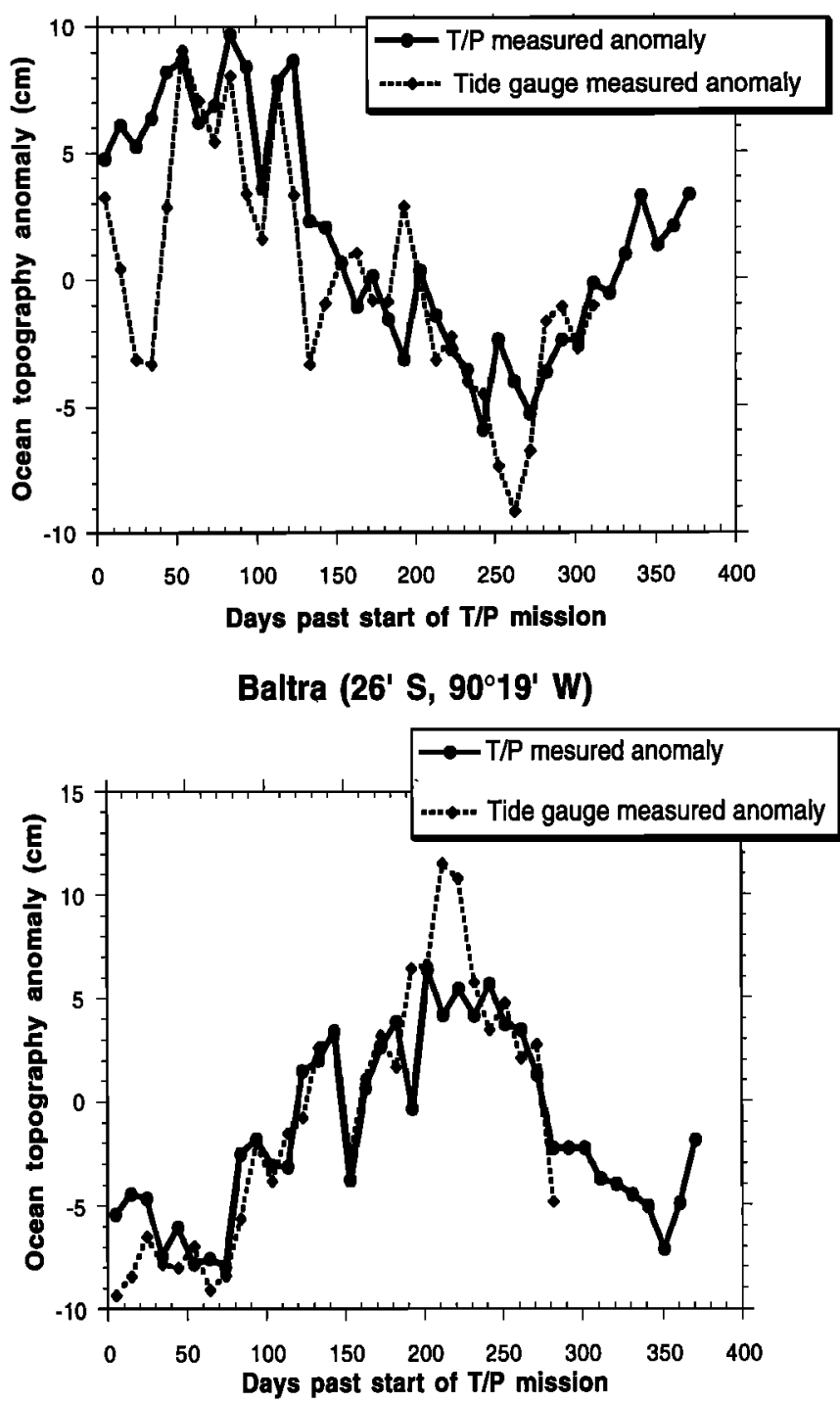

Figure 3. Comparisons of dynamic ocean topography variations observed by TOPEX/POSEIDON with sea level variations observed by two in situ tide gauges in the equatorial Pacific. The inverted barometer correction has not been applied to either dataset.

dynamic ocean topography computed globally from TOPEX/ POSEIDON altimeter data to determine the accuracy of the longwavelength ocean signals TOPEX/POSEIDON observes. The tide gauges represent portions of the Pacific Ocean (13 sites) and the Indian Ocean ( 6 sites). The tide gauge daily averaged filtered data available were further averaged into 10-day means consistent with the TOPEX/POSEIDON repeat cycles for better comparison. Anomalies were made of the tide gauge data by removing a mean calculated from October 23,1992, to the end of the available data, generally the end of June 1993. Anomalies were made from the TOPEX/POSEIDON topography computed at each site by removing a local mean over the same time span. Removing a mean from each data set removed the unknown reference frame from the tide gauge data and removed the major portion of the geoid error from the ocean topography measurement.

It should be noted that several factors related to the measurements can affect the comparisons. First, some tidal signal may
Table 2a. Comparison of Ocean Topography Variations From TOPEX/POSEIDON With Pacific Island Tide Gauge Data

\begin{tabular}{lcc}
\hline \multicolumn{1}{c}{ Tide Gauge Site } & RMS of Residuals, cm & Correlation \\
\hline Baltra, Galapagos Islands & 2.7 & 0.91 \\
Kanton, Kiribati & 2.8 & 0.82 \\
Rabaul, New Guinea & 2.7 & 0.75 \\
Christmas, Kiribati & 3.7 & 0.71 \\
Majuro, Marshall Islands & 4.7 & 0.71 \\
Pohnpei, Micronesia & 2.5 & 0.53 \\
Rikitea, French Polynesia & 4.7 & 0.58 \\
Kapingamarangi, Micronesia & 5.1 & 0.55 \\
Honiara, Solomon Islands & 3.8 & 0.51 \\
Penhryn, Cook Islands & 4.3 & 0.37 \\
Malakal, Belau & 6.7 & 0.32 \\
Papeete, French Polynesia & 3.6 & 0.25 \\
Fr. Frigate Shoals, USA & 6.8 & 0.15 \\
\hline
\end{tabular}

Total RMS $=4 \mathrm{~cm}$.

remain in the altimeter measurement because of small model deficiencies in the area, although these are estimated to be no larger than $5 \mathrm{~cm}$ in limited regions. Second, the altimeter data are edited around land where the water depth is less than $100 \mathrm{~m}$, so it measures the deep ocean sea surface. However, the tide gauges are near shore, typically in water only a few hundred meters deep, and will observe changes not observable in the deep ocean, such as larger wind-driven changes in the sea level. Finally, the closest point of the TOPEX/POSEIDON ground track can be up to 300 $\mathrm{km}$ away from the tide gauge location, and changes of the order of tens of centimeters are not uncommon over this distance.

Considering the differences in measurements that have been described, Tables $2 a$ and $2 b$ indicate that the temporal variations in the in situ tide gauge measurements and the altimetric ocean topography measurements show remarkable agreement, especially in the Pacific Ocean. The total RMS of the differences is $4.9 \mathrm{~cm}$, while in the Pacific it is slightly lower at $4 \mathrm{~cm}$. Correlations range from a low of 0.1 to as high as 0.9 at Baltra, which gives strong credence to the variations shown in Figure 3. Two-thirds of the tide gauge sites have a correlation of more than 0.5 with the altimeter data, while almost half have a correlation greater than 0.6 . Even the station with the largest RMS difference (Port Louis in the Indian Ocean) has a very high correlation, 0.73 , indicating that while the magnitude of the variation observed might not have been consistent, the sense of the variation was.

Table 2b. Comparison of Ocean Topography Variations From TOPEX/POSEIDON With Indian Ocean Island Tide Gauge Data

\begin{tabular}{lcc}
\hline \multicolumn{1}{c}{ Tide Gauge Site } & RMS of Residuals, cm & Correlation \\
\hline Rodrigues, Mauritius & 4.7 & 0.73 \\
Port Louis, Mauritius & 9.6 & 0.73 \\
Gan, Maldives & 2.8 & 0.59 \\
Hanimaadhoo, Maldives & 4.4 & 0.61 \\
Hulule, Maldives & 4.3 & 0.28 \\
Salalah, Oman & 7.3 & 0.11 \\
\hline
\end{tabular}

Total RMS $=6 \mathrm{~cm}$. 


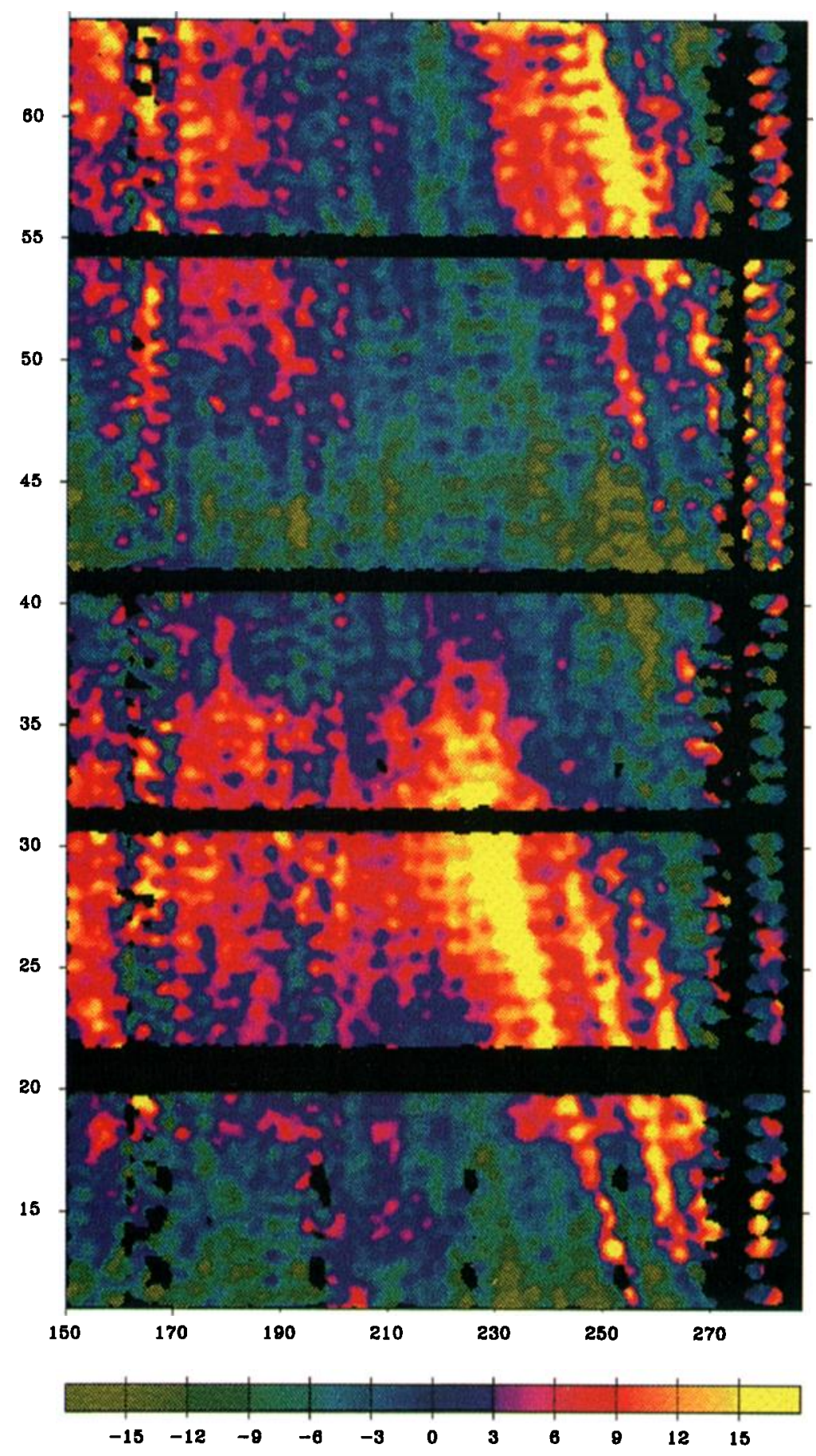

Plate 8. Changes in the surface topography westward movement. The $x$ axis is east longitude and the $y$ axis is the TOPEX/POSEIDON repeat cycle number, increasing upward. Black bands indicate data from POSEIDON altimeter, which were not processed, or land. The features of interest are the sloping patterns in the right portion of the figure. The propagation velocity for each feature is approximately $18 \mathrm{~cm} / \mathrm{s}$.

The agreement in these comparisons is one measure of the accuracy with which temporal variations in the long-wavelength ocean topography can be measured. However, since removing the local mean also removes the geoid in the area, this analysis does not give an overall accuracy for the absolute value of the dynamic ocean topography. If the tide gauge anomalies are assumed to be correct, this comparison does indicate that the sea surface topography anomalies recovered with the altimeter data have an RMS precision of better than $5 \mathrm{~cm}$. Since both techniques have inherent error sources, the accuracy of the altimeter-defined dynamic topography anomalies should be better than $5 \mathrm{~cm}$.

\section{Conclusion}

The analysis of data from the first year of the TOPEX/ POSEIDON mission indicates that the orbit error is not a limiting error source, and the results are consistent with the reported radial orbit accuracy of better than $4 \mathrm{~cm}$ RMS. The results observed 
using the geophysical data records are limited by tide model and geoid model error. However, after using the first year of GDR data to determine an improved tide model, the data can be used to observe time-varying ocean surface phenomena at the 5-cm level. This value is based on comparisons with Tropical Ocean and Global Atmosphere (TOGA) tide gauge data in the Pacific and Indian Oceans. With the improved orbit and tide model, the absolute dynamic topography measurements are limited primarily by the geoid model error over the ocean regions, which is estimated to be $15 \mathrm{~cm}$ RMS for wavelengths of $1600 \mathrm{~km}$ and longer. However, analysis indicates that errors can be much larger in specific regions, inducing significant error into the recovered ocean circulation.

By using the mean annual sea surface topography as a reference, the TOPEX/POSEIDON data can be used to examine the temporal changes in the 10-day sea surface topographies. This sequence of changes clearly defines subdecimeter variations in the equatorial Pacific corresponding to an equatorial Kelvin wave traveling west to east with a phase speed of approximately $3 \mathrm{~m} / \mathrm{s}$. The wave began in the western pacific on or about December 21 , 1992, and reached the coast of South America approximately 50 days later. Variations in the current system in the Indian Ocean were also observed. The temporal variations observed by the TOPEX altimeter data have been confirmed by comparison with Pacific and Indian Ocean tide gauge data.

The analysis of the first year of TOPEX GDR data indicates that the promise of satellite altimetry is being achieved by the TOPEX/POSEIDON mission. The full mission promises a view of the ocean which is unprecedented in its geographical and temporal resolution and which has the requisite measurement accuracy to support the current global change investigations.

Acknowledgments. The authors gratefully acknowledge the contribution of Gary Mitchum in providing the TOGA tide gauge data. This research was supported by the TOPEX/POSEIDON Project at the NASA Jet Propulsion Laboratory under contract JPL 958122. Additional computing resources for this work were provided by the University of Texas System Center for High Performance Computing.

\section{References}

Callahan, P. S., TOPEX/POSEIDON NASA GDR Users Handbook, JPL Rep. D-8590, Rev. C, Jet Propuls. Lab., Pasadena, Calif., 1993.

Cartwright, D., and R. Ray, Ocean tides from Geosat altimetry, J. Geophys. Res., 95, 3069-3090, 1990.

Dickman, S. R., Theoretical investigation of the oceanic inverted barometer response, J. Geophys. Res., 93, 14941-14946, 1988.

Engelis, T., and R. H. Rapp, Global ocean circulation patterns based on Seasat altimeter data and the GEM-L2 gravity field, Mar. Geophys., 7, 55-67, 1984.

Fu, L.-L., E. J. Christensen, C. A. Yamarone Jr., M. Lefebvre, Y. Menard, M. Dorrer, and P. Escudier, TOPEX/POSEIDON mission overview, J. Geophys. Res., this issue.

Giese, B. S., J. A. Carton, and L. Holl, Sea level variability in the eastern tropical Pacific as observed by TOPEX and Tropical Ocean and Global Atmosphere-Tropical Atmosphere Ocean, J. Geophys. Res., this issue.

Kim, M. C., C. K. Shum, and B. D. Tapley, An altimetric mean sea surface and its spectral analysis, in Proceedings of the Second ERS-1 Symposium, Space at the Service of Our Environment, pp. 1047-1051, European Space Agency, Paris, 1993.

Koblinsky, C. J., R. S. Nerem, R. G. Williamson, and S. M. Klosko, Global scale variations in sea surface topography determined from satellite altimetry, in Sea Level Changes: Determination and Effects, Geophys. Monogr. Ser., vol. 69, edited by P. L. Woodworth et al., pp. 155-165, AGU, Washington, D.C., 1992.

Levitus, S., Climatological atlas of the world ocean, NOAA Prof. Pap. 13, U.S. Govt. Print. Office, Washington, D.C., 1982.
Ma, X. C., C. K. Shum, R. J. Eanes, and B. D. Tapley, Determination of ocean tides from the first year of TOPEX/POSEIDON altimeter measurements, J. Geophys. Res., this issue.

Miller, L., R. E. Cheney, and B. C. Douglas, Geosat altimeter observations of Kelvin waves and the 1986-1987 El Nifo, Science, 239, 52-54, 1988.

Nerem, R. S., B. D. Tapley, and C. K. Shum, Determination of the ocean circulation using Geosat altimetry, J. Geophys. Res., 95, 3163-3179, 1990.

Nerem, R. S., et al., Gravity model development for TOPEX/POSEIDON: Joint gravity models-1 and 2, J. Geophys. Res., this issue.

Parke, M. E., R. H. Stewart, D. L. Farless, and D. E. Cartwright, On the choice of orbits for an altimetric satellite to study ocean circulation and tides, J. Geophys. Res., 92, 11693-11707, 1987.

Philander, S. G., El Nifo, La Nifia and the Southern Oscillation, pp. 121-156, Academic, San Diego, Calif., 1990.

Rapp, R. H., Y. M. Wang, and N. K. Pavlis, The Ohio State 1991 geopotential and sea surface topography harmonic coefficient models, Rep. 410, Dep. Geod. Sci. and Surv., Ohio State Univ., Columbus, August 1991.

Ray, R. D., Global ocean tide models on the eve of TOPEX/POSEIDON, IEEE Trans. Geosci. Remote Sens., 31, 355-363, 1993.

Shum, C. K., B. D. Tapley, D. N. Yuan, J. C. Ries, and B. E. Schutz, An improved model for the Earth's gravity field, Proceedings IAG Symposium 103, Gravity, Gradiometry and Gravimetry, pp. 97-108, Springer-Verlag, New York, 1990.

Shum, C. K., D. P. Chambers, J. C. Ries, B. D. Tapley, and D. N. Yuan, Determination of large scale ocean circulation and its variations using satellite altimetry, Gravimetry and Space Techniques Applied to Geodynamics and Ocean Dynamics, Geophys. Monogr. Ser., vol. 82, edited by B. E. Schutz et al., pp. 21-32, AGU, Washington, D.C., 1994.

Stewart, R. H., L. L. Fu, and M. Lefebvre, Science opportunities from the TOPEX/POSEDON mission, JPL Publ. 86-18, Jet Propuls. Lab., Pasadena, Calif., 1986.

Tai, C. K., On the quasigeostrophic ocean response to atmospheric pressure forcing: The inverted barometer pumping, NOAA Tech. Memo., NOS OES 005, April 1993.

Tai, C. K., and C. Wunsch, An estimate of global absolute dynamic topography, J. Phys. Oceanogr., 14, 457-463, 1984.

Tapley, B. D., R. S. Nerem, C. K. Shum, J. C. Ries and D. N. Yuan, Determination of the general ocean circulation from a joint gravity field solution, Geophys. Res. Lett., 15, 1109-1112, 1988.

Tapley, B. D., et al., The JGM-3 gravity model, paper presented at Annual Meeting, Eur. Geophys. Soc., Grenoble, France, April 1994.

Tapley, B. D., et al., Precision orbit determination for TOPEX/ POSEIDON, J. Geophys. Res., this issue.

TOPEX Science Working Group, Satellite altimetric measurements of the ocean, Doc. 400-111, Jet Propuls. Lab., Pasadena, Calif., 1981.

Wunsch, C., An interim relative sea surface for the North Atlantic Ocean, Mar. Geod., 5, 103-119, 1981.

Wunsch, C., and A. E. Gill, Observations of equx'orially trapped waves in Pacific sea level variations, Deep Sea Res., 23, 371-390, 1976.

Wunsch, C., and E. M. Gaposchkin, On using satellite altimetry to determine the general circulation of the ocean with application to geoid improvement, Rev. Geophys., 18, 725-745, 1980.

Wyrtk, K., Sea level and the seasonal fluctuations of the equatorial currents in the western Pacific Ocean, J. Phys. Oceanogr., 4, 91-103, 1974.

Zlotnicki, V., L. Fu, and W. Patzert, Seasonal variability in global sea level observed with Geosat altimetry, J. Geophys. Res., 94, 17959-17969, 1989.

D. P. Chambers, R. J. Eanes, J. C. Ries, C. K. Shum, and B. D. Tapley, The University of Texas at Austin, Center for Space Research C0605, Austin, TX 78712. (e-mail: tapley@utcsr.ae.utexas.edu).

R. H. Stewart, Department of Oceanography, Texas A\&M University, College Station, TX 77840. (e-mail: stewart@astra.tamu.edu).

(Received May 6, 1994; revised July 13, 1994;

accepted July 13, 1994.) 